\title{
Fatores contextuais da CIF como ferramentas de análise das implicaçóes da aquisiçáo de deficiência física por pessoas atendidas pela Terapia Ocupacional
}

\author{
Rosé Colom Toldrá, Ana Cristina Fagundes Souto \\ Curso de Terapia Ocupacional, Departamento de Fisioterapia, Fonoaudiologia e Terapia Ocupacional, Faculdade \\ de Medicina, Universidade de São Paulo - USP, São Paulo, SP, Brasil
}

\begin{abstract}
Resumo: O presente artigo analisa as implicações da aquisição de deficiência física a partir das situações vividas por um grupo de pessoas atendidas pela Terapia Ocupacional, utilizando-se como referência a Classificação Internacional de Funcionalidade, Incapacidade e Saúde - CIF, com ênfase nos fatores contextuais. Participaram do estudo 11 pessoas adultas e idosas com deficiência física, decorrentes de quadros neurológicos, acompanhados pela Terapia Ocupacional no Centro de Docência e Pesquisa da Universidade de São Paulo, no período de 2009 a 2010. Trata-se de investigação qualitativa do tipo exploratória, realizada por meio de estudo documental e entrevista semiestruturada para aplicação dos componentes da CIF. Nas funções corporais, as alterações são diversas, tanto mentais como relacionadas ao movimento, e quando associadas aos fatores contextuais podem resultar em diferentes níveis e tipos de incapacidade, impedindo a participação nas situações de vida. A análise dos fatores contextuais possibilita identificar e relacionar aspectos pessoais e do ambiente cuja interação dinâmica reflete processos produtores de funcionalidade/incapacidade, fazendo da CIF um norteador valioso para estudos e desenvolvimento de práticas em reabilitação que considerem os diferentes aspectos que envolvem a realidade de vida da pessoa.
\end{abstract}

Palavras-chave: Pessoas com Deficiência; Classificação Internacional de Funcionalidade, Incapacidade e Saúde; Participação Social; Reabilitação; Terapia Ocupacional.

\section{Contextual factors of the ICF as a tool for analysis of the implications of physical disability for a group of patients under Occupational Therapy care}

\begin{abstract}
This article analyzes the implications of the acquisition of physical disability on everyday life situations of persons under occupational therapy care using the International Classification of Functioning, Disability and Health - ICF, with emphasis on contextual factors. The study included 11 adults and elderly with physical impairments resulting from neurological disorders who were under Occupational Therapy care at the Center for Teaching and Research at the University of Sao Paulo from 2009 to 2010. It's an exploratory qualitative research conducted through documentary study and semi-structured interview for the administration of the ICF components. Changes in body functions are diverse, both mental and related to movement, and when coupled with contextual factors may result in different levels and types of disabilities, preventing participation in life situations. The analysis of contextual factors helps to identify and relate personal and environmental aspects and their dynamic interaction reflects processes that may cause disability, establishing the ICF as a valuable guide for research and development of rehabilitation practices that consider the different aspects of the reality of a person's life.
\end{abstract}

Keywords: Disabled Persons; International Classification of Functioning, Disability and Health; Social Participation, Rehabilitation; Occupational Therapy.

Autor para correspondência: Rosé Colom Toldrá, Universidade de São Paulo, Rua Cipotânea, 51, Cidade Universitária, Butantã, CEP 05360000, São Paulo, SP, Brasil, e-mail: rosetoldra@usp.br

Recebido em 30/11/2011; Revisão em 18/10/2012; Aceito em 7/11/2012. 


\section{Introdução}

As disfunçóes neurológicas no adulto e no idoso ocupam os primeiros lugares de morbidade e mortalidade no Brasil (MALTA et al., 2006), contribuindo para o aumento das doenças crônicas. Sua ocorrência na fase adulta gera grandes desafios aos profissionais da saúde, tendo em vista que se trata de um dos estágios mais complexos e dinâmicos da vida, requerendo o desenvolvimento de práticas de atençâoo articuladas às especificidades dessa fase (HASSELKUS, 2002) e ao impacto que a deficiência representa para o indivíduo e sua família.

O predomínio das doenças crônicas não transmissíveis decorrentes do atual quadro de transição epidemiológica e demográfica brasileira requer o desenvolvimento e a agregação de tecnologias (MALTA; MERHY, 2010) que viabilizem a manutenção da funcionalidade e a qualidade de vida dessa população, exigindo dos profissionais da saúde que repensem sua inserção nos serviços e nas propostas de ação.

Essa realidade mostra que os indicadores epidemiológicos clássicos, baseados na mortalidade, são pouco sensíveis para descrever os estados de saúde da população, tendo em vista a modificação do padrão de doenças, com predomínio de doenças crônicas e de deficiências (BUNUUALES; DIEGO; MORENO, 2002), colocando-se a Classificação Internacional da Funcionalidade, Incapacidade e Saúde como um instrumento valorizado para esse uso.

Considerando o aumento de pessoas com deficiência física decorrente de doenças crônicas, dentre elas as que apresentam quadros neurológicos, e a importância da contribuição da Terapia Ocupacional na atenção a essa população, o presente estudo visa analisar, a partir da Classificação Internacional de Funcionalidade, Incapacidade e Saúde - CIF (ORGANIZAÇÃO..., 2003), as implicaçôes da aquisição da deficiência física nas situaçóes vividas por pessoas atendidas pela Terapia Ocupacional.

\section{Compreensão da funcionalidade humana e da incapacidade segundo a CIF}

Na perspectiva do modelo biopsicossocial adotado pela CIF, a incapacidade é considerada como o resultado de um conjunto complexo de condiçôes, muitas das quais criadas pelo ambiente social, e não um atributo de um indivíduo. Esse entendimento vem para superar o modelo puramente médico, que considera a incapacidade como um problema da pessoa, causado diretamente pela doença, por trauma ou outro estado de saúde no âmbito individual (ORGANIZAÇÃO..., 2003).

$\mathrm{Na}$ CIF, a funcionalidade e a incapacidade são consideradas como resultado das interaçóes dinâmicas entre estados de saúde (doenças, distúrbios e lesôes) e os fatores contextuais (pessoais e ambientais), conforme pode ser visualizado na Figura 1.

A classificação propóe o entendimento da funcionalidade e da incapacidade por meio da descrição de situaçóes experimentadas pelos indivíduos e relacionadas às atividades humanas e aos aspectos que as restringem. Tal proposição representa uma transformaçáo de uma abordagem

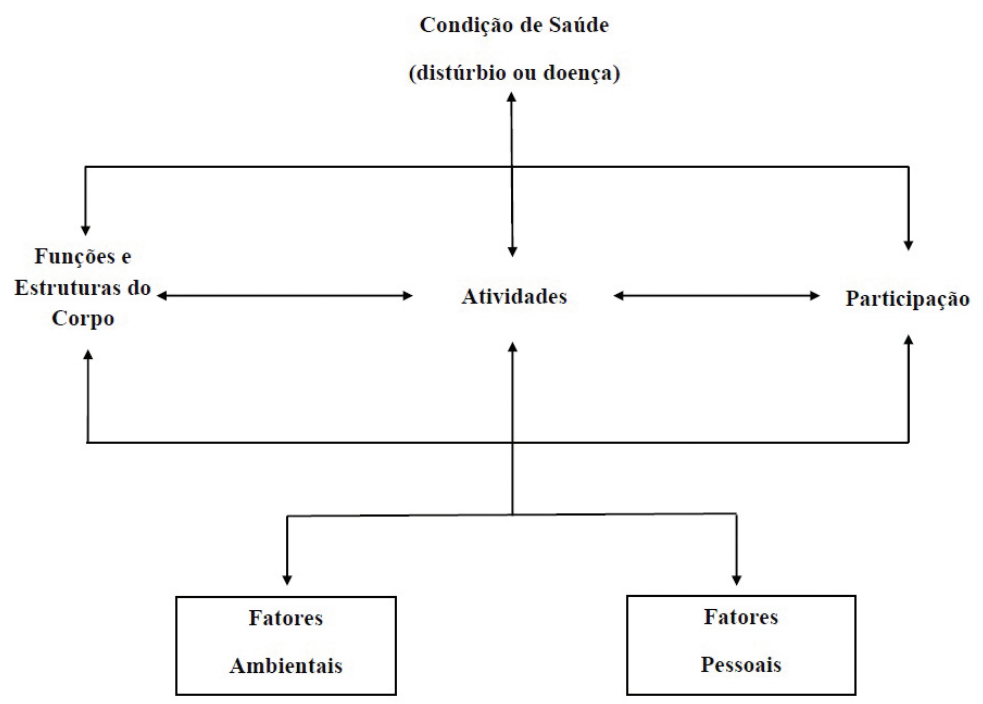

Figura 1. Interações entre os componentes da CIF. 
baseada nas consequências das doenças para uma visão ampliada e complexa das dimensôes da saúde.

A Terapia Ocupacional se identifica com esse entendimento de saúde e com os conceitos empregados pela CIF, o que favorece uma aproximação com a própria linguagem, a identidade e a prática do terapeuta ocupacional, quando comparada com outras áreas profissionais (TOLDRÁ, 2003; DARZINS; FONE; DARZINS, 2006). Isso vem reforçar a importância de sua utilização e familiarização para a prática profissional.

Um estudo realizado por Stamm et al. (2006), comparando três modelos de terapia ocupacional (Modelo de Ocupação Humana, Modelo de Desempenho Ocupacional Canadense e Modelo de Desempenho Ocupacional Australiano), mostrou que existe grande relação entre os conceitos da CIF e os conceitos referidos pelos modelos estudados. Isso favorece aos terapeutas ocupacionais o uso dessa classificação em sua prática, assim como os conhecimentos sobre os quais a profissáo se baseia colocam esses profissionais como fundamental nas equipes multiprofissionais e serviços, na medida em que qualificam a utilização da classificação na prática profissional.

Outros estudos apontam a necessidade de promover pesquisas para identificar como a CIF pode ser aplicada na Terapia Ocupacional e suas implicações na prática clínica (HAGLUND; HENRIKSSON, 2003; DARZINS; FONE; DARZINS, 2006).

Para facilitar a compreensão e a articulaçáo dos princípios da CIF no decorrer do texto, faz-se necessário retomar os principais conceitos empregados pela classificação. Dos componentes de funcionalidade e incapacidade, fazem parte o corpo (funções dos sistemas e estruturas), atividade e participação e os fatores contextuais.

O corpo é constituído pelas funçōes fisiológicas dos sistemas orgânicos (mentais, sensoriais etc.) e as estruturas do corpo são as partes anatômicas, como órgãos, membros e seus componentes. Os problemas nas funções ou nas estruturas do corpo (uma alteração importante ou uma perda) são considerados deficiências e, portanto, parte de um estado de saúde. O modelo da CIF pressupóe a existência de condiçôes e estados de saúde propriamente ditos expressas pelo uso combinado com a Classificação Estatística Internacional de Doenças e Problemas Relacionados à Saúde conhecida como CID-10 (DI NUBILA; BUCHALLA, 2008).

A participação é entendida como o envolvimento em uma situação de vida e as restriçóes de participação são os problemas experimentados pelo indivíduo nas diversas situaçôes que envolvem o cotidiano.

Os fatores contextuais referem-se ao "contexto completo da vida de um indivíduo" (ORGANIZAÇÃO..., 2003, p. 243) e são compostos por fatores ambientais e fatores pessoais.

- Os fatores ambientais dizem respeito a todos os aspectos externos ou extrínsecos que fazem parte da vida da pessoa, com impacto na funcionalidade. Os fatores ambientais incluem: produtos e tecnologias; ambiente natural e mudanças ambientais feitas pelo ser humano; apoios e relacionamentos; serviços; sistemas sociais e políticas.

- Os fatores pessoais são constituídos pelas características particulares e de situação de vida do indivíduo. Os fatores pessoais não são codificados na CIF devido à diversidade de aspectos que podem ser encontrados, porém não são menos importantes, pois têm influência na funcionalidade. Fazem parte dos aspectos pessoais: gênero, idade, raça, preparo físico, estilo de vida, hábitos, escolaridade, origem social e outras condições de saúde.

Funcionalidade engloba todas as funçóes do corpo e a capacidade de o indivíduo realizar atividades e tarefas do cotidiano, assim como sua participação na sociedade. Incapacidade é um termo genérico que indica dificuldades nas funçôes corporais, limitaçôes no desempenho das atividades de autocuidado e restrições na participação social, denotando os aspectos negativos da interação entre o indivíduo e os fatores contextuais.

As contribuições apontadas pela utilização da CIF são diversas. O emprego da classificação proporcionaria bases para criar modelos explicativos e valorizar os diferentes aspectos do processo vivenciado (VÁZQUEZ-BARQUERO et al., 2001). Também permitiria desenvolver uma abordagem terapêutica mais abrangente, visando à qualidade e à individualidade da atenção, da descrição e da classificação do processo saúdedoença (SAMPAIO et al., 2005). Sua utilizaçáo favoreceria a criação de evidências (TOLDRÁ et al., 2010), permitiria o seguimento em componentes de atividade e participaçáo (PAGANIZZI, 2007) e possibilitaria uma referência para selecionar avaliaçóes de caráter biopsicossocial e classificar potencialidades (SIMONELLI et al., 2010).

Sua estrutura conceitual e o vocabulário podem auxiliar os terapeutas ocupacionais e as equipes de saúde a avaliarem e aperfeiçoarem suas práticas 
(DARZINS; FONE; DARZINS, 2006), oferecendo uma base científica para as consequências de condiçôes ou estados de saúde e uma linguagem comum para as comunicações entre os diferentes profissionais e países.

A aplicação da classificação permite melhor compreensão da interaçáo das condiçôes de saúde do indivíduo com o contexto, ou seja, permite a análise da produção dos processos de incapacidade/funcionalidade. Essa abordagem leva ao questionamento das práticas clínicas e do próprio sentido da reabilitação, apontando para o desenvolvimento de uma visão ampliada de saúde que considere os diferentes aspectos que envolvem a realidade de vida da pessoa.

\section{Materiais e métodos}

O estudo foi desenvolvido no Centro de Docência e Pesquisa (CDP) do Departamento de Fisioterapia, Fonoaudiologia e Terapia Ocupacional da FMUSP no período de 2009 a 2010 e dele participaram 11 pessoas, entre adultos e idosos com deficiência física, atendidas no ambulatório de Terapia Ocupacional. Essas pessoas foram encaminhadas pelo setor de Fisioterapia do próprio centro, pelo Hospital Universitário e, ainda, por procura espontânea.

Para a coleta de dados foi adotado o estudo documental, a partir de leitura e análise dos dados dos registros realizados semanalmente nos prontuários das pessoas atendidas pela Terapia Ocupacional. Além do estudo documental de prontuário, foi realizada entrevista semiestruturada visando maior aprofundamento das informaçôes referentes aos aspectos contextuais, ou seja, pessoais e ambientais. $\mathrm{Na}$ entrevista foram combinadas questôes fechadas e abertas, sendo que essas últimas favoreceram que as pessoas discorressem sobre o tema de forma mais livre (MINAYO, 2007). As entrevistas foram gravadas e transcritas. Nelas utilizou-se como eixo norteador a checklist da CIF, sendo que para este artigo foram selecionados os aspectos referentes aos fatores contextuais, pela influência na participaçáo social. Assim, para organização, apresentação e análise dos dados foram escolhidos os componentes descritos pela CIF funções e estruturas corporais, fatores ambientais e pessoais, tendo em vista o objetivo de analisarem-se as implicações da aquisição de deficiência física no cotidiano dessas pessoas. Todos esses componentes foram codificados até o segundo nível. Os dados referentes às funções e às estruturas do corpo foram coletados a partir dos aspectos referidos pelos participantes, acrescidos das observaçóes realizadas durante o acompanhamento em Terapia
Ocupacional. Quanto aos fatores ambientais, a coleta centrou-se nos aspectos referidos pelos participantes, apoiados nos dados das entrevistas e de prontuário, identificando-os como facilitadores ou barreiras. No entanto, não ocorreu a aplicação de qualificadores, pois as perguntas eram abertas e não foi pedido aos entrevistados que graduassem as barreiras e os facilitadores.

Utilizou-se de depoimentos que ilustram as barreiras e os facilitadores nas atividades e na participação social, dada a importância conferida às experiências pelos indivíduos. Para melhor identificação dos dados dos pesquisados, foram utilizadas as iniciais dos nomes, que se encontram relacionados na Tabela 1 e nos depoimentos apresentados no decorrer do texto.

A pesquisa se situa no campo da investigação qualitativa do tipo exploratória (GIL, 2006), por possibilitar um melhor conhecimento da realidade empírica referente às situaçôes vividas pelos participantes do estudo.

Esta pesquisa foi aprovada pela Comissão de Ética em Pesquisa do Hospital das Clínicas e da FMUSP sob protocolo de pesquisa n. 0643/09. O estudo documental e as entrevistas foram realizados após ciência e autorizaçáo dos sujeitos da pesquisa por meio de Termo de Consentimento Livre e Esclarecido.

\section{Resultados}

Para o desenvolvimento do estudo são apresentados os diferentes aspectos relatados pelos pesquisados, de acordo com os componentes da CIF, enfatizando as principais implicaçôes dos fatores contextuais.

A caracterização dos participantes do estudo quanto ao diagnóstico e aos fatores pessoais auxilia na compreensão da influência dos fatores contextuais, conforme Tabela 1.

Dentre os fatores pessoais, destacam-se os aspectos sociodemográficos como: o nível de escolaridade de sete pesquisados, que possuem o ensino fundamental incompleto; o estado civil, sete são separados ou divorciados; e quanto à renda, 10 têm algum tipo de renda proveniente de aposentadoria, auxílio-doença ou Benefício de Prestaçáo Continuada (BPC) no valor de cerca de um salário mínimo. Quanto à idade, nove têm menos de 60 anos e desses, cinco tem menos de 45 anos, sendo, portanto, considerados adultos jovens.

Quanto aos diagnósticos e às sequelas motoras apresentadas, temos sete sujeitos com hemiparesia, um com paraparesia, um com paraplegia e dois com tetraparesia. Correspondente a essas 


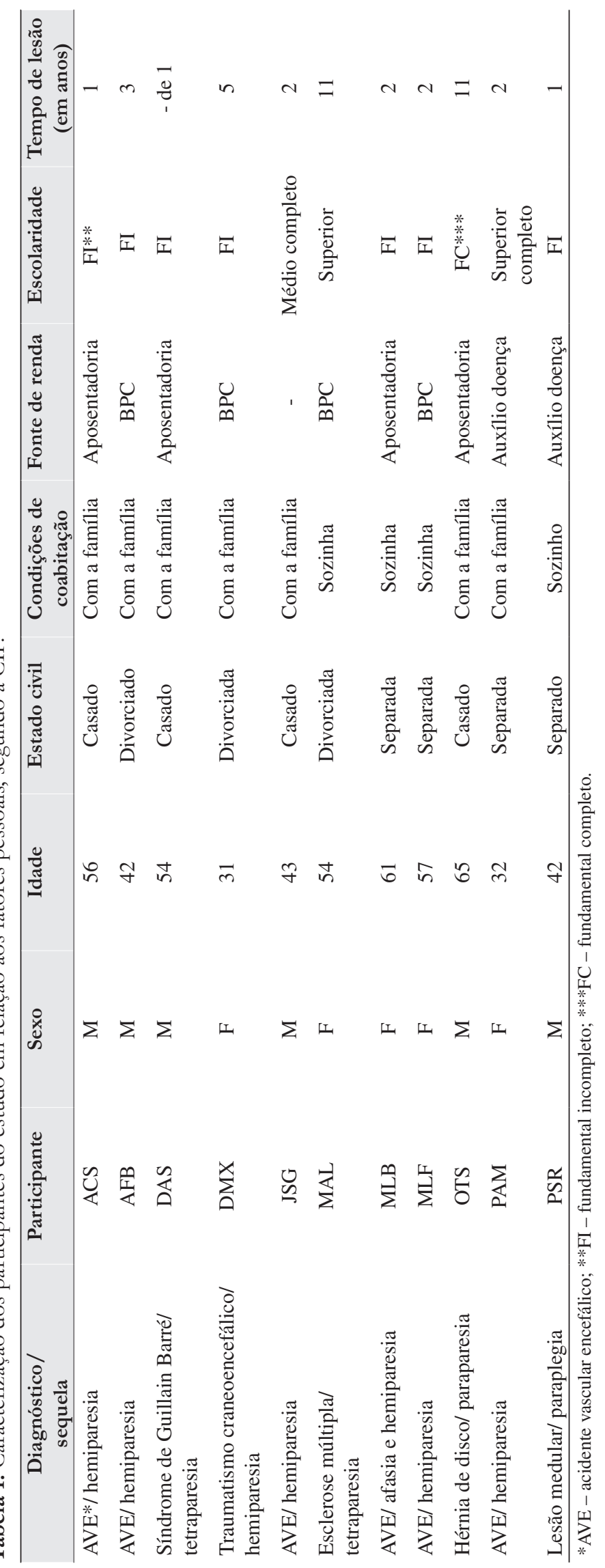


condições, apresentam-se as alteraçôes relativas ao componente corpo: funçóes e estruturas do corpo, conforme Tabela 2. As funçóes mais frequentemente acometidas estáo dispostas da seguinte maneira: funçôes neuromusculoesqueléticas e relacionadas ao movimento (b730, b760, b770 - 100\%), funções mentais (b130 - 100\%; b126, b156 - 90,91\%), seguidas das funçōes sensoriais e dor (b270 - 90,91\%; b265 - 90,91\%). Com relação às estruturas corporais, temos $100 \%$ dos participantes com acometimento de membros inferiores (s750), seguidos de membros superiores (s730 - 81,82\%) e cérebro (s110 - 72,73\%).

Os fatores ambientais podem ser considerados como facilitadores ou barreiras para o desempenho das atividades e da participação social, conforme interação com os componentes de funcionalidade/ incapacidade. Tais fatores encontram-se organizados na CIF em sequência, ou seja, do ambiente mais imediato ao mais amplo, e estáo dispostos em ambiente físico, social e de atitudes. Dentre os fatores ambientais citados, destacam-se neste estudo os produtos e tecnologias, apoio e relacionamentos, atitudes e serviços, sistemas e politicas, conforme demonstra a Tabela 3.

\section{Discussão}

As alteraçôes das funçóes mentais aliadas às funções sensoriais e dor e às funções neuromusculoesqueléticas e relacionadas ao movimento indicam que os acometimentos são múltiplos e afetam a vida das pessoas de diferentes maneiras, o que mostra a necessidade de intervençóes que respondam integralmente a essas demandas.

Tendo em vista os limites para classificar os aspectos pessoais na CIF e sua grande relevância para

Tabela 2. Principais deficiências referidas pelos participantes do estudo, relativas à função e estrutura do corpo, segundo a CIF.

\begin{tabular}{|c|c|c|c|}
\hline \multicolumn{2}{|r|}{ Função e estrutura } & & \multirow[t]{2}{*}{$\%$} \\
\hline b1 & Funções mentais & & \\
\hline b126 & Funções do temperamento e da personalidade & $10 / 11$ & 90,91 \\
\hline b130 & Funções da energia e do impulso - Motivação & $11 / 11$ & 100,00 \\
\hline b134 & Funções do sono & $3 / 11$ & 27,27 \\
\hline b140 & Funções da atenção & $5 / 11$ & 45,45 \\
\hline b144 & Funções da memória & $5 / 11$ & 45,45 \\
\hline b152 & Funções emocionais & $8 / 11$ & 72,73 \\
\hline b156 & Funções da percepção - Percepção tátil & $10 / 11$ & 90,91 \\
\hline b167 & Funções mentais da linguagem & $3 / 11$ & 27,27 \\
\hline b2 & Funções sensoriais e dor & & \\
\hline b265 & Função tátil & $10 / 11$ & 90,91 \\
\hline b270 & Funções sensoriais relacionadas à temperatura e outras & $10 / 11$ & 90,91 \\
\hline b280 & Sensação de dor - Dor localizada & $8 / 11$ & 72,73 \\
\hline b3 & Funções da voz e da fala & & \\
\hline b398 & Funções da voz e da fala, outras & 3/11 & 27,27 \\
\hline b6 & Funções genitourinárias e reprodutivas & & \\
\hline b620 & Funções urinárias - Continência urinária & $2 / 11$ & 18,18 \\
\hline b640 & Funções sexuais & $3 / 11$ & 27,27 \\
\hline b7 & Funções neuromusculoesqueléticas e relacionadas ao movimento & & \\
\hline b730 & $\begin{array}{l}\text { Funções relacionadas à força muscular - Força dos músculos de um lado } \\
\text { do corpo - Força dos músculos da metade inferior do corpo }\end{array}$ & $11 / 11$ & 100,00 \\
\hline b760 & Funções relacionadas ao controle dos movimentos voluntários & $11 / 11$ & 100,00 \\
\hline b770 & Funções relacionadas ao padrão da marcha & $11 / 11$ & 100,00 \\
\hline s1 & Estruturas do Sistema Nervoso & & \\
\hline s110 & Estrutura do Cérebro & $8 / 11$ & 72,73 \\
\hline s120 & Medula espinhal e estruturas relacionadas & $3 / 11$ & 27,27 \\
\hline s7 & Estruturas relacionadas ao movimento & & \\
\hline s730 & Extremidade superior & 9/11 & 81,82 \\
\hline s750 & Extremidade inferior & $11 / 11$ & 100,00 \\
\hline s760 & Estrutura do tronco - Coluna vertebral & $3 / 11$ & 27,27 \\
\hline
\end{tabular}


Tabela 3. Principais facilitadores e barreiras referidos pelos participantes do estudo, relativas aos fatores ambientais, segundo a CIF.

\begin{tabular}{|c|c|c|c|c|c|}
\hline \multicolumn{2}{|r|}{ Fatores Ambientais } & Facilitador & $\%$ & Barreira & $\%$ \\
\hline e1 & Produtos e tecnologia & & & & \\
\hline e110 & Produtos e substâncias para uso pessoal - Medicamentos & 11 & 100 & 2 & 18 \\
\hline e115 & $\begin{array}{l}\text { Produtos e tecnologia para uso pessoal na vida } \\
\text { diária - Talheres, tábua de corte, adaptação para pé equino }\end{array}$ & 7 & 64 & 2 & 18 \\
\hline e120 & Produtos e tecnologias para mobilidade - Bengala & 8 & 73 & 1 & 9 \\
\hline e140 & $\begin{array}{l}\text { Produtos e tecnologia para atividades culturais, } \\
\text { recreativas e esportivas }\end{array}$ & 1 & 9 & 3 & 27 \\
\hline e150 & $\begin{array}{l}\text { Produtos e tecnologia usados em projeto, arquitetura e } \\
\text { construção de edifícios para uso público }\end{array}$ & 1 & 9 & 10 & 91 \\
\hline e160 & $\begin{array}{l}\text { Produtos e tecnologia relacionada ao uso e exploração do } \\
\text { solo - Desenvolvimento da zona urbana }\end{array}$ & - & - & 11 & 100 \\
\hline e3 & Apoio e relacionamentos & & & & \\
\hline e310 & Família imediata & 8 & 73 & 6 & 55 \\
\hline e325 & $\begin{array}{l}\text { Conhecidos, companheiros, colegas, vizinhos e membros } \\
\text { da comunidade }\end{array}$ & 5 & 45 & 5 & 45 \\
\hline $\mathrm{e} 340$ & Cuidadores e assistentes pessoais & 3 & 27 & 3 & 27 \\
\hline e355 & Profissionais da saúde & 11 & 100 & 6 & 55 \\
\hline e360 & Outros profissionais & 3 & 27 & - & \\
\hline e4 & Atitudes & & & & \\
\hline e410 & Atitudes individuais de membros da família imediata & 4 & 36 & 4 & 36 \\
\hline e425 & $\begin{array}{l}\text { Atitudes individuais de conhecidos, companheiros, } \\
\text { colegas, vizinhos e membros da comunidade }\end{array}$ & 4 & 36 & 8 & 73 \\
\hline e445 & Atitudes individuais de estranhos & 1 & 9 & 5 & 45 \\
\hline $\mathrm{e} 450$ & Atitudes individuais dos profissionais de saúde & 11 & 100 & 4 & 36 \\
\hline e460 & Atitudes sociais & - & - & 11 & 100 \\
\hline e5 & Serviços, sistemas e políticas & & & & \\
\hline e540 & Serviços, sistemas e políticas de transporte & - & - & 11 & 100 \\
\hline e570 & Serviços, sistemas e políticas da previdência social & 3 & 27 & 2 & 18 \\
\hline e575 & Serviços, sistemas e políticas de suporte social geral & 3 & 27 & 2 & 18 \\
\hline e580 & Serviços, sistemas e políticas de saúde & 4 & 36 & 5 & 45 \\
\hline
\end{tabular}

os estudos e as práticas em Terapia Ocupacional, esses aspectos serão apresentados, pois complementam os demais domínios previstos pela classificação e permitem sugerir a interferência desses fatores na vida das pessoas (NUNES, 2008; NICKEL et al., 2010). Em relação aos fatores pessoais, observou-se que alguns limitam a participação social. Destaca-se que dentre os 11 sujeitos, nove encontram-se em fase produtiva, sendo que apenas um realiza trabalhos esporádicos, de forma autônoma, nesse caso para complementação da renda obtida pelo BPC. Os participantes do estudo representam uma máo de obra potencial que se encontra excluída do mercado de trabalho, o que aponta para o impacto da deficiência na vida profissional e na independência econômica das pessoas e seus familiares.

Com a identificação dos fatores pessoais e dos principais componentes referentes ao corpo, é possível analisar de forma mais apropriada a influência dos fatores ambientais no cotidiano de vida dos participantes do estudo, ilustrada por meio dos depoimentos, de acordo com as principais situaçóes vivenciadas por esses participantes em termos de barreiras e facilitadores.

Dentre os aspectos que sugerem maior participaçáo social e pressupóem a existência de uma rede de suporte cotidiana, encontra-se a coabitação (4) e a existência de cônjuge (3).

O nível de escolaridade médio ou acima (3) aparece como potencial protetor no que tange às condiçóes de saúde e acesso aos serviços, considerando que

os efeitos do nível de instrução se manifestam das mais diferentes formas: na percepção dos problemas de saúde; na capacidade de entendimento das informaçôes sobre saúde; na adoção de estilos de vida saudáveis; no consumo e utilização dos serviços de saúde; e na adesão aos procedimentos terapêuticos (BRASIL, 2008, p. 46). 


\subsection{Produtos e tecnologias}

Os produtos e tecnologias de assistência são compreendidos como qualquer produto, instrumento, equipamento ou tecnologia adaptada ou especialmente projetada para melhorar a funcionalidade (ORGANIZAÇÃO..., 2003). Como principais facilitadores, as pessoas referiram os medicamentos (e1101 - 100\%). Destacou-se o emprego de tecnologias para uso pessoal nas atividades da vida diárias (e115-64\%), confeccionadas a partir de materiais alternativos e sob a orientação de terapeuta ocupacional, as quais possibilitaram maior grau de independência na execução das tarefas, motivaçáo para o resgate de algumas atividades e melhores condiçôes para o engajamento nas situaçóes do dia a dia, como relatado a seguir: "Eu achei bacana aquela tábua de cortar carne, me ajudou bastante" (DMX). Para a marcha, todos que utilizavam a bengala (e120 - 82\%) a reconhecem como facilitadora, pela segurança e possibilidade de desempenho da funçáo com maior independência, embora expressem as vivências subjetivas negativas decorrentes de seu uso: "Odeio usar a bengala, mas não tem jeito" (MLF); "Nunca aceitei" (JSG; PAM); "Não sou doente" (PAM), revelando que o significado dado ao produto reflete a construção social em torno da deficiência como uma doença. Ao mesmo tempo, surgem exemplos em que o uso do dispositivo de auxílio para a marcha (scooter) de uma pessoa com maior tempo de convivência com a deficiência denota superação do conflito: "Tenho de me conformar em usar esse carrinho... Esta barreira já venci” (OTS).

$\mathrm{O}$ uso da cadeira de rodas, enquanto produto e tecnologia que deveria facilitar a vida das pessoas, foi considerado por três pesquisados como inadequado, por criar barreiras na rotina de vida deles. Um deles expressa as restrições que vive:

Perde um pouco da sua liberdade, se eu tivesse uma cadeira boa, poderia até estar tentando sair... não tenho oportunidade de ir na casa dos meus amigos, que moram no mesmo bairro, por causa dessa limitação da cadeira (PSR).

O pesquisado identifica, ainda, outras restrições decorrentes do modelo inadequado de cadeira de rodas, doada informalmente, e seu impacto no cotidiano:

Com essa cadeira não dá... Tô bem limitado... Não tenho muitas atividades: levanto, tomo banho, depois fico na rua, debaixo da árvore, vendo os passarinhos cantar, converso com a molecada, com algumas pessoas, essa é a minha atividade (PSR).
Os fatores ambientais correspondentes ao planejamento e ao desenvolvimento de espaço urbano trazem barreiras aos participantes (e150 - 91\%) para a circulação no próprio bairro devido à insuficiente manutençáo do espaço urbano (falta de asfalto, buracos e entulho nas ruas) e, também, aos terrenos acidentados, tráfego excessivo em região não planejada etc. Essas condições adversas trazem limites para o desempenho ao provocar medo de cair, insegurança de atravessar a rua:

Tenho medo de andar, porque a rua é muito movimentada, eu moro em frente a uma comunidade. Tenho medo dos carros, tenho medo de atravessar a rua... Teve um dia que eu demorei cinco minutos pra atravessar (MLF);

e dificultam a circulação e a apropriação de um território subjetivo importante, o bairro de moradia, como apontado por outro participante:

Eu gostaria de estar onde todo mundo está. Nas calçadas tudo é o contrário de inclusivo, nada é adaptado, eu não posso abrir a porta e sair, o ambiente não colabora (MAL).

Os pesquisados retratam o que muitos vivem:

Se for sair na rua, não tem como. Não tem calçada rebaixada pras cadeiras... Antes, quando não tava debilitado, a gente não percebia isso. Mas quando a gente tá vivendo percebe que é bem difícil a vida de um deficiente! (DAS).

Em relação a esse aspecto, outro participante aponta preferir andar no shopping, o que contribui para a restrição de uso dos espaços públicos em detrimento dos espaços privados de consumo:

Na rua, todos os obstáculos... Tem de procurar andar num lugar mais plano... tudo é subida, por isso que eu gosto do shopping! No shopping, eu ando sem o carrinho: puxa vida, eu posso andar. Eu posso, também, pôr a muleta dentro do carrinho, fazer compras, pegar as coisas e carregar (OTS).

O envolvimento em atividades culturais, recreativas e esportivas é dificultado pela falta de adaptação ou de previsão de equipamentos, produtos e tecnologias que permitam a participaçáo de pessoas com deficiência física, como aponta o depoimento:

Se eu for pra um parque, eu vou ficar parado lá, só dão acesso para o cadeirante, mas não tem atividade. Pode entrar lá dentro, mas não tem nada pra você fazer lá. Eu quero participar, entendeu? (PSR). 
A experiência ressalta que o simples acesso não é suficiente e transforma o uso de parques públicos em algo destituído de sentido, na medida em que não possibilita compartilhar as experiências com os demais, dificultando o desempenho dessa atividade social.

Isso aponta a necessidade de se considerar a acessibilidade para além dos aspectos físicos e arquitetônicos, incluindo a possibilidade de receber pessoas com diferentes condiçôes de saúde, o que engloba tanto a perspectiva atitudinal como a preparação e a oferta de atividades amplas e diversas.

Um dos pesquisados com engajamento prévio em atividades de recreação e lazer menciona mudanças na sua participação no clube, passando de jogador de bola para apoio do técnico do time: "Não consigo mais correr, mas dou orientaçáa... Vai passando uma idade ou você arruma alguma coisa para fazer dentro do clube ou você para" (AFB). Por um lado, refere-se à deficiência relacionada ao controle dos movimentos voluntários do lado afetado e sua limitação para as atividades que exigem essa função, por outro, sua capacidade de adaptaçáa, por meio do engajamento em novas situaçóes que favorecem o relacionamento com as pessoas: "Já que a minha mão parou, a minha comunicaçâo faz eu me movimentar, eu tenho de usar o que não perdi" (AFB). A valorização da função de comunicação permite assumir um novo papel social como orientador no treino de futebol, repercutindo em resgate das atividades voltadas à recreação e ao esporte e uma recriaçáo da forma de atuar e se relacionar com o meio, transformando-o com suas açóes e sendo modificado por ele.

A experiência mostra o aprendizado da própria pessoa, na medida em que desloca o foco da atenção a um corpo patológico individual para um corpo relacional (ROCHA, 2006), em que ocorre a valorização das próprias potencialidades, contribuindo para a sua funcionalidade.

\subsection{Apoios e relacionamentos}

Dentre os fatores ambientais, assinalam-se os apoios e os relacionamentos recebidos pelos participantes. Tais fatores são considerados pela CIF como apoio físico ou emocional prático; proteção e assistência; relacionamento com outras pessoas, na casa, no local de trabalho, ou outros aspectos das atividades da vida diária (ORGANIZAÇÃO..., 2003). Destacam-se no estudo aqueles recebidos da família, de membros da comunidade e de profissionais de saúde.

Nota-se que os apoios e relacionamentos referentes às relaçóes familiares (e310) aparecem como um facilitador importante (73\%), porém assumem um lugar ambíguo, estando também entre as principais barreiras (55\%), com situaçôes que vão desde o abandono até o apoio à superação. Os exemplos a seguir ilustram essas situaçóes, como o enfrentamento de separação no casamento: "Ela achava que eu estava atrapalhando por causa da minha deficiência" (AFB); a existência de suporte financeiro recebido da família em contraposição à ausência de suporte afetivo: "Recebo algum apoio financeiro, mas isso realmente não satisfaz" (MAL); e a mudança no papel de cuidadora do neto, para o de ser cuidada, resultando no distanciamento da filha:

Minha filha não me aceita... porque antes de eu ficar doente, eu tomava conta da minha neta. A minha filha não vai na minha casa e ela mora no mesmo quintal" (MLF).

Para outros, o apoio da família foi constante e fundamental para a superação das fases mais difíceis e o retorno às atividades:

Minha familia, minha mulher dá muito incentivo, apoia bastante, me ajudou bastante! [...] Se não fossem eles... teria ficado jogado, porque foram eles que me deram todo o apoio" (JSG). "Meus filhos, minha esposa... foram fundamentais, estiveram sempre do meu lado. Meus irmãos me deram bastante assistência" (DAS). "Minha família é muito boa... me deram muita força (OTS).

$\mathrm{Na}$ convivência social com membros da comunidade (e325), os facilitadores (45\%) e as barreiras (45\%) são equivalentes. Assinalam-se os contatos ocorridos a partir do uso de transporte público como um facilitador: "Motoristas esperam para subir e cobrador fica de olho, quando vou descer, ele já sabe e avisa o motorista" (MLB). Já para outros, a mesma atividade indica barreiras, o que demonstra a necessidade de investimento na formação dos condutores e dos cobradores, evitando-se que o caráter facilitador dependa unicamente da maior ou menor disponibilidade pessoal dos funcionários dos transportes coletivos. Apontam-se, também, dificuldades na convivência com membros da comunidade no que se refere ao uso do assento reservado para as pessoas com deficiência:

As pessoas são sem educação, não respeitam. Eu tinha bastante dificuldade em segurar no ônibus, nem sempre eu podia sentar, porque tavam ocupados os lugares de pessoas com deficiência e as pessoas não dão lugar não (JSG).

Também no apoio e nos relacionamentos se identificam constrangimentos na medida em que muitas pessoas nas situações de convivência 
social expressam o desconhecimento em relação às dificuldades de comunicaçáo verbal. Ter de fornecer alguma informação ou responder e não ser compreendido é uma situação de tensão que pode levar ao abandono de algumas atividades e cenários sociais importantes, como deixar de frequentar a escola de samba (MLB); evitar comunicar-se: "As pessoas não me entendem" (PAM); e relacionar-se com as pessoas: "Eu tenho vergonha de mim, eu tenho vergonha de sair na rua... Minhas vizinhas ficam tudo me olhando, eu não gosto" (MLB), impactando negativamente na realização das atividades e nas relaçóes interpessoais. Ao voltar a frequentar locais, também são vivenciadas barreiras:

Quando eu chegava lá, os caras comentavam: que fatalidade! Eu já não gostava que os caras falassem, me tratassem dessa maneira. Mas só a minha presença lá já intimidava (AFB).

Com os profissionais de saúde, os apoios e relacionamentos (e355) variaram ao longo dos tratamentos e do tempo de convivência com a atual condição de saúde, prevalecendo os aspectos considerados facilitadores (100\%) frente às barreiras (55\%). Destaca-se como facilitador o acolhimento, descrito como apoio, para o enfrentamento e a elaboração da nova situação decorrente da aquisição da deficiência, e expresso por profissionais que marcaram a vida das pessoas pelo sentimento de confiança e esperança transmitidos e pelos estímulos recebidos: "Uma pessoa maravilhosa, né. Uma pessoa que marcou muito na minha vida, porque me tratou desde o início... sabe o que está fazendo" (AFB). Em especial, temos os profissionais da área de reabilitação (Terapia Ocupacional e Fisioterapia), na qual se destaca a repercussão tanto nos aspectos psicológicos quanto funcionais: "A TO e a Fisio me ajudaram muito no meu desenvolvimento" (DMX). Também é reconhecido como importante o encaminhamento a outros serviços de assistência à saúde, a programas sociais e a profissionais especializados.

Quanto às barreiras, foram citados o diagnóstico tardio pelos sintomas iniciais serem considerados psicológicos:

Fui mal atendido, o primeiro médico não diagnosticou minha doença, me deu alta, disse que era psicológico, por isso eu acredito que tenha ficado com sequela (JSG);

e assistência profissional insatisfatória: "Foi um descuido do médico mudar o meu medicamento, tive o AVC" (PAM).

A experiência de oferecimento de apoio por parte de um participante nos círculos sociais que frequenta permite novas trocas sociais, subvertendo os estereótipos relacionados às pessoas com deficiência como sujeitos-alvo, recebedores de ações e ajuda, com pouco a oferecer. Nesse caso, o participante usa a própria experiência para orientar jovens do clube quanto ao perigo de consumir bebida alcoólica, por acreditar que "uma boa conversa com a garotada ajuda" (AFB). Ele explora, assim, sua capacidade de comunicação e de interaçáo interpessoal em vez de atividades como pular, correr e jogar bola. Sua atitude de ajuda leva-o à convivência com os jovens e se converte em autogratificação, transformando uma condição de incapacidade devido à deficiência física em uma de participação favorecida pelos fatores contextuais, nesse caso tanto os ambientais como os pessoais. Tal situação reafirma a funcionalidade/ incapacidade dos indivíduos como resultantes de uma relação dinâmica entre ele e seus fatores contextuais e desmistifica a ideia de que a deficiência (no nível do corpo) necessariamente implica incapacidade e vice-versa (DI NUBILA; BUCHALLA, 2008).

\subsection{Atitudes}

$\mathrm{Na}$ CIF, as atitudes são consideradas consequências observáveis de costumes, práticas, ideologias, valores, normas e crenças que influenciam o comportamento individual e a vida social em todos os seus aspectos, envolvendo tanto as atitudes positivas como as negativas (ORGANIZAÇĀO..., 2003).

As atitudes da família (e410) assinalam barreiras (36\%) e facilitadores $(36 \%$,) variando da infantilização e rejeição até o incentivo. Faz-se necessário reafirmar constantemente o lugar na família: "Eu não sou criança! Eu não sou bebezinho! Minha cabeça está boa!” (PAM). A não aceitação da deficiência e o distanciamento do convívio familiar, na medida em que aumenta o grau de dependência: "Conto cada vez menos com a família" (MAL). Para outros, destaca-se a uniâo familiar como elemento estratégico para o enfrentamento das incertezas frente à atual condição de saúde e a reorganização na vida de todos os membros (JSG; DAS; OTS; ACS).

Os participantes expressam como as atitudes sociais (e425) repercutem em limitação nas atividades e restriçōes de participação (73\%), como, por exemplo:

Vou em alguns lugares e não me sinto muito à vontade... Encosto a cadeira num cantinho e fico lá por causa da minha limitação... As pessoas se distanciam um pouco, elas te cumprimentame vão conversar com outras pessoas, você fica meio isolado porque deixa de fazer parte do mundo das pessoas (PSR). 
As barreiras enfrentadas nas diferentes interaçóes sociais com conhecidos podem reforçar a ideia negativa de diferença, gerando um movimento de autossegregação, expresso por PSR com o desejo de permanecer entre "iguais": "Se eu começasse a frequentar lugares que tivessem pessoas na mesma condição talvez fosse melhor para comunicação" (PSR). O pouco tempo de convivência com a nova condição de saúde, menos de um ano, e, ainda, por se sentir mais reservado depois de ter adquirido a deficiência física são, nesse caso, fatores pessoais que se somam às barreiras atitudinais acima destacadas.

Exercer os direitos previstos na Constituição é algo vivenciado com constrangimento:

Algum tipo de preconceito existe... Quando você chega em uma fila em uma casa lotérica, você tem prioridade. Mas as pessoas olham assim, às vezes não falam nada, mas a gente percebe que ninguém está gostando daquilo. Você vai pra frente, porque é um direito que assiste, né. Mesmo que a pessoa não fale nada você percebe... (DAS).

O uso de transporte público traz atitudes e sentimentos contraditórios e desconcertantes, como sentir-se humilhado quando as pessoas cedem lugar no ônibus, respeitando a preferência (MLB), ou vergonha pelo fato de ficar na parte dianteira do ônibus (PAM), ou ser necessário justificar o uso do banco preferencial e do bilhete especial: "Como você conseguiu a carteirinha?" (PAM); ou descer pela porta dianteira (JSR; PAM). Evidencia-se o dilema entre o exercício de direitos e a falta de sensibilizaçáo social, pelo ainda escasso convívio e pelo desconhecimento das particularidades das pessoas com deficiência física, mostrando a necessidade de açóes mais amplas nesse sentido.

Os pesquisados discorrem ainda sobre as barreiras atitudinais enfrentadas no convívio social (e460 - 100\%): vergonha das pessoas os olharem na rua (JSG; MLF), embaraço por serem questionados quanto à embriaguez, pela marcha típica do hemiplégico (MLF; MLB), e pela percepção da atitude de pena manifestada pelas pessoas, devido à dependência de outros.

\subsection{Serviços, sistemas e políticas}

Quanto a serviços, sistema e políticas, destacam-se os serviços de saúde, transporte e social. No serviço de transporte público adaptado (e540), as barreiras (100\%) citadas por todos referem-se à demora em ser atendido:
Foi dificil... demorou bastante o Atende... Tive que ir de táxi muitas vezes para não perder o tratamento... Depois que a gente consegue fica muito bom!" (DAS);

à restrição de horário, o que impossibilita seguir alguns tratamentos; e a indisponibilidade do sistema para atividades que não as terapêuticas/ reabilitativas, criando barreiras para a convivência social e aumentando a sensação de dependência de outrem:

Deixei de procurar o grupo que en fazia parte por causa da dificuldade de botar a cadeira de rodas no carro e depender de carro dos outros... Eu percebo que estou atrapalhando com esse negócio de carona" (MAL).

Frequentar serviços de suporte social territorial (e575) foi apontado como facilitador (27\%), podendo ser ilustrado por uma das participantes pelo engajamento em atividades, ampliação das redes e identificação de papéis sociais não ligados à deficiência: "Tem várias atividades, vejo gente, como é que eu vou falar? São pessoas que têm doenças e que são avós como eu" (MLB). Também são reconhecidos pelo apoio oferecido em casa: "No Paraisópolis tem muito programa social... O pessoal não sabe, mas tem" (DAS).

O desconhecimento dos suportes existentes demonstra a falta de informação e de possibilidades de acesso aos próprios direitos: "Fui a semana passada no cinema e paguei meia [mostrando a carteirinha] [...] Não sabia ... eu pagava sempre inteira" (PAM).

Para os serviços de previdência social (e570), destacam-se a concessão do BPC, citada como facilitador (27\%), para autossubsistência e também como insuficiente (18\%) para suprir as necessidades, como a remuneração de um cuidador (MAL).

No âmbito da saúde (e580), surgem situaçóes facilitadoras (36\%) pelos encaminhamentos para outros tratamentos e pelos serviços prestados: "Todos os hospitais em que eu cheguei sempre fui bem tratada, bem atendida... Esse negócio de saúde, às vezes demoram, mas de resto tudo bem" (MLF); ou pelo sistema de distribuição de medicação. As barreiras, nesse aspecto, referem-se à demora para marcaçáo de consultas, à impossibilidade de realização de exames e à falta de atendimento adequado: "Eu tava todo paralisado e não fui atendido" (DAS); precárias condições de assistência: "Peguei infeç̧ão hospitalar e complicou minha saúde" (ACS). Todas essas condiçóes denotam um descaso na assistência à saúde e a necessidade de seu aperfeiçoamento. 


\section{Considerações finais}

Pode-se notar, nas diferentes situações apresentadas, que a utilizaçáo da CIF contribuiu para a análise da produção dos processos de incapacidade/ funcionalidade vivenciados pelas pessoas com deficiência física, mesmo considerando as limitaçôes do estudo, decorrente do número reduzido de participantes e da abordagem mais abrangente e panorâmica dos fatores contextuais.

A interação dos diferentes componentes da CIF, apresentada pelas narrativas, permitiu uma compreensão ampliada dos aspectos que envolvem a vida dessas pessoas e suscitam reflexóes mais abrangentes acerca da importância dos produtos e das tecnologias, do apoio e dos relacionamentos, das atitudes profissionais e sociais, das açôes no âmbito dos serviços e do papel de sistemas e políticas.

Por fim, a utilização da CIF favoreceu a identificação e a análise das necessidades das pessoas e a interaçáo com os fatores ambientais e pessoais, tornando-se útil para a seleção de formas de avaliação, desenvolvimento de estratégias, tanto terapêuticas como as voltadas à participação social, constituindo-se, dessa forma, como um norteador valioso para estudos e o desenvolvimento de práticas no campo da reabilitação.

\section{Referências}

BRASIL. Ministério da Saúde. Comissão Nacional sobre Determinantes Sociais da Saúde. As causas sociais das iniquidades em saúde no Brasil. Brasília, 2008. 216 p. (Relatório final). Disponível em: <http://www.cndss. fiocruz.br/pdf/home/relatorio.pdf>. Acesso em: 3 set. 2012. BUÑUALES, M. T. J.; DIEGO, P. G.; MORENO, J. M. M. La Clasificación Internacional del Funcionamiento, de Discapacidad y de la Salud (CIF) 2001. Revista Española de Salud Pública, Madrid, v. 76, n. 4, p. 271-279, 2002.

DARZINS, P.; FONE, S.; DARZINS, S. The International Classification of Functioning, Disability and Health can help to structure and evaluate therapy. Australian Occupational Therapy Journal, Melbourne, v. 53, n. 2, p. 127-131, 2006. http://dx.doi. org/10.1111/j.1440-1630.2006.00580.x

DI NUBILA, H. B. V.; BUCHALLA, C. M. O papel das Classificaçóes da OMS - CID e CIF nas definiçóes de deficiência e incapacidade. Revista Brasileira de Epidemiologia, São Paulo, v. 11, n. 2, p. 324-335, 2008.

GIL, A. C. Métodos e técnicas de pesquisa social. São Paulo: Atlas, 2006.

HAGLUND, L.; HENRIKSSON, C. Concepts in occupational therapy in relation to the ICF. Occupational Therapy International, London, v. 10, n. 4, p. 253-268, 2003. http://dx.doi.org/10.1002/oti.189
HASSELKUS, B. R. Introdução às populaçôes de adultos e idosos. In: NEISTADT, M. E.; CREPEAU, E. B. Willard \& Spackman Terapia Ocupacional. 9. ed. Rio de Janeiro: Guanabara Koogan, 2002. p. 607-615.

MALTA, D. C.; MERHY, E. E. O percurso da linha do cuidado sob a perspectiva das doenças crônicas não transmissíveis. Interface: Comunicação, Saúde, Educação, Botucatu, v. 14, n. 34, p. 593-605, 2010.

MALTA D. C. et al. A construção da vigilância e prevenção das doenças crônicas não transmissíveis no contexto do Sistema Único de Saúde. Epidemiologia e Serviços de Saúde, Brasília, v. 15, n. 15, p. 47-65, 2006.

MINAYO, M. C. S. O desafio do conhecimento: pesquisa qualitativa em saúde. São Paulo: Hucitec, 2007.

NICKEL, R. et al. Estudo descritivo do desempenho ocupacional do sujeito com doença de Parkinson: o uso da CIF como ferramenta para classificação da atividade e participação. Acta Fisiátrica, São Paulo, v. 17, n. 1, p. 13-17, 2010.

NUNES, C. M. P. A terapia ocupacional e as disfunções neurológicas da idade adulta e da velhice: CIF em casos clínicos. In: DRUMMOND, A. F.; REZENDE, M. B. Intervençôes da terapia ocupacional. Belo Horizonte: Editora UFMG, 2008. p. 95-137.

ORGANIZAÇÃO MUNDIAL DA SAÚDE - OMS. CIF: Classificação Internacional de Funcionalidade, Incapacidade e Saúde. São Paulo: EDUSP, 2003.

PAGANIZZI, L. Rehabilitación de personas con trastornos adictivos. In: CONGRESO ARGENTINO E CONGRESO LATINO-AMERICANO DE TERAPIA OCUPACIONAL, 7., 2007, Mar del Plata. Anais... Buenos Aires: Asociación Marplatense de Terapistas Ocupacinales, 2007.

ROCHA, E. F. Reabilitação de pessoas com deficiência. São Paulo: Roca, 2006.

SAMPAIO, R. F. et al. Aplicação da Classificação Internacional Funcionalidade, Incapacidade e Saúde (CIF) na prática clínica do fisioterapeuta. Revista Brasileira de Fisioterapia, São Carlos, v. 9, n. 2, p. 129-136, 2005.

SIMONELLI, A. P. et al. Proposta de articulação entre abordagens metodológicas para melhoria do processo de reabilitação profissional. Revista Brasileira de Saúde Ocupacional, São Paulo, v. 35, n. 121, p. 64-73, 2010. http://dx.doi.org/10.1590/S0303-76572010000100008

STAMM, T. A. et al. Exploration of the link between conceptual occupational therapy models and the International Classification of Functioning, Disability and Health. Australian Occupational Therapy Journal, Melbourne, v. 53, n. 1, p. 9-17, 2006.

TOLDRÁ, R. C. Reflexôes acerca da Terapia Ocupacional na atenção à pessoa portadora de deficiência física, In: PÁDUA, E. M. M.; MAGALHĀES, L. V. Terapia Ocupacional: teoria e prática. Campinas: Papirus, 2003. p. 49-60.

TOLDRÁ, R. C. et al. Facilitadores e barreiras para o retorno ao trabalho: a experiência de trabalhadores 
atendidos em um Centro de Referência em Saúde do Trabalhador - SP, Brasil. Revista Brasileira de Saúde Ocupacional, São Paulo, v. 35, n. 121, p. 10-22, 2010. http://dx.doi.org/10.1590/S0303-76572010000100003
VÁZQUEZ-BARQUERO, J. L. et al. Clasificación Internacional del Funcionamiento, de Discapacidad y de la Salud (CIF): antecedentes, marco conceptual y estructura. Papeles Médicos, Zaragoza, v. 10, n. 4, p. 177-184, 2001.

\section{Contribuição dos Autores}

A concepção da pesquisa e do texto é de Rosé Colom Toldrá. A redação, análises e organização das fontes foi feita conjuntamente pelas duas autoras. 